\title{
Individual and Organizational Impact of Enterprises Resources Planning System in Healthcare Sector
}

\author{
ASAD ILYAS*, MUHAMMAD FIAZ**, AND ASMA TAYYABA* \\ RECEIVED ON 11.02.2015 ACCEPTED ON 16.09.2015
}

\begin{abstract}
Use of ERPS (Enterprise Resource Planning System) in healthcare sector has positive impacts. The purpose of this research is to find out the individual and organizational impact in healthcare sector. Hypotheses were postulated that the use of ERPS has positive individual and organizational impacts. A research questionnaire was used to test these hypotheses which have twelve dimensions for both impacts. This instrument was adopted from literature and self-administrated to 504 individuals with response rate of $60 \%$ and only $56 \%$ of questionnaires were used. The results of this study revealed that the use of ERPS has positive individual and organizational impacts. This study will help the healthcare organizations to find out impacts of ERPS in healthcare sector and also to better understand the individual and organizational impacts.
\end{abstract}

Key Words: Enterprise Resource Planning Systems, Individual Impact, Organizational Impact.

\section{INTRODUCTION}

$\mathrm{E}$ RPS are integrated systems having single database which connects all departments of an organization for better operations and decision making so in order to speed up the processes of an organization there has been a substantial improvement in information systems which can be recognized as ERPS [1]. An organization can successfully implements ERPS in a short time period but it cannot be assumed that it can achieve benefits from it shortly as it needs time for the realization of its actual benefit. The high cost and complexity associated with ERPS had forced organizations to reconsider their strategy for procuring and implementing it [2]. Most importantly the implementation of ERPS causes some organizations to enjoy considerable improvements while others may face disruptive changes in organization's existing system [3].
ERPS is the fastest growing and central development in information technology sector [4]. The demand for the application of ERPS is growing due to pressure arises from competition between organizations to be converted into a low cost producer, enhancing the ability for global competition, desire for business re-engineering and revenue growth expectation [4]. For the positive influence on organization activity usually it spends larger share on information systems [5]. Organizations usually report positive impact of information systems implementation [6]. ERPs are designed to boost up competitiveness of an organization by upgrading its ability to produce precise and timely information. All the cases of ERPS implementation are not successful as the failure rate of ERPS implementation ranges from $40-60 \%$ but still

*Post-Graduate Student, and *Professor,

Institute of Business \& Management, University of Engineering \& Technology, Lahore.

Mehran University Research Journal of Engineering \& Technology, Volume 35, No. 3, July, 2016 [p-ISSN: 0254-7821, e-ISSN: 2413-7219] 
organizations implement it for better communication and planning [7]. Numerous risks exist in ERPS implementation like re-engineering of process, relational databases and business process interdependence linkages [8]. Risks in an organization come from its environment including structure of organization and conditions in which system is applied [9]. The failure of ERPS can be due to many factors like absence of proper business management, inappropriate planning and alteration in business goals during ERPS implementation [10]. The problems related to ERPS implementation can be alleviated through reengineering of business process and use of careful communication [11].

HERPS (Healthcare Enterprise Resource Planning System) can be defined as an integrative system that covers widespread information of healthcare unit including the patient statistics, clinical facts and management of finances [12]. Healthcare units are complex institutions that consist of large departments for patient care and "Enterprise Resource Planning" in these institutions can assists in better-quality of healthcare practices and services [13]. The application of information system in healthcare has resulted in better management of health services, increased patient care quality and improved decision making in administration [14]. ERPS is adopted as it possesses three essential properties i.e. ERPS encompasses a multifunctional perspective and covers many different areas of healthcare organization as it has a modular structure and system integration by which a same data set can be shared by many departments [15].

Healthcare units require integrated systems which permit the procedure planning to be applied on patients while instantaneously examining the necessary capacity [16]. Several studies have been carried out that have analyzed the use of ERPS on healthcare units [17-18]. The success factors for the implementation of ERPS in small healthcare organization has been studied by Trimmer, et. al. [18] while McGinnis, et. al. [17] reported the case of a small hospital in rural area that had a successful implementation of ERPS. There are many threats and challenges for healthcare organizations which are adopting ERPS as structure of these organizations are very complex and have various functional areas that make difficult for ERPS to be implemented effectively [19]. So the culture of an organization and user perception has a direct impact on success of ERPS implementation.

\section{Literature Review}

\subsection{Individual Impact}

Individual impact is related to enhancement in efficiency and abilities of individual person in an organization while using ERPS [20]. In this research it is related to impact on doctors, nurses etc. individual impact has four aspects i.e. learning, awareness, effective decision making and individual productivity [20]. First aspect is about learning of system's user while using ERPS. Learning is the most important aspect for healthcare professionals and ERPS helps the individuals to learn new practices. The second aspect is about awareness of job that is performed by the healthcare professionals and the use of ERPS helps the user to be more aware of their job's description. Third important aspect in individual impact is about effectiveness in decision making while using ERPS. The use of ERPS provides all the data and information which are required for effective decision making. Lastly this dimension includes enhancement of individual productivity of system's users while using ERPS. In healthcare organization the overall performance of an organization is very much dependent of individual performance of healthcare professionals. The use of ERPS enhances the individual productivity of users which ultimately enhances healthcare service quality. In this research individual impact includes "Learning through the presences of ERPS”, “Awareness about Job Related Information", "Effectiveness in Job" and "User's Productivity" as dimensions given by Gable et al., [20]. 


\subsection{Organizational Impact}

The benefits received by an organization through the use of information system are known as the organizational impact. Information technology impact on organization is checked through the performance of business [21-22] which further leads to the value of business [23]. The measurement of organizational impact is carried out as strategic value and competitive advantage [24], capacity utilization, effectiveness and efficiency of an organization and market value [25]. In this research organizational impact includes "Cost Effectiveness", "Reduced Staff Cost", "Reduced Admin Cost", "Improvement in overall Productivity", "Improvement in Output", "Increased Capacity", "Better E-Governance" and "Improved Business Process" as dimensions given by Gable, et. al. [20].

\subsection{Research Methodology}

On the basis of previous studies following research hypotheses are postulated

H1: The use of ERPS has positive individual impact.

H2: The use of ERPS has positive organizational impact.

In this research a questionnaire was used as originally developed by Gable, et. al. [20]. Only dimensions for individual and organizational impact are used. This questionnaire has four question for individual impact and eight dimensions for organizational impact along with four questions for demographics i.e. gender, age, experience and job title All questions are used on five point likert scale i.e. $1=$ strongly disagree and $5=$ for strongly agree. This questionnaire is self-administrated in 504 individuals with response rate of $60 \%$ as only 302 individuals returned filled questionnaire but only 279 were utilized which is $56 \%$ only.

\section{RESULTS AND DISCUSSION}

\subsection{Demographic Variables}

Gender: 123 female respondents responded the survey instrument which is $44.1 \%$ of total data collected and 156 male respondents responded the survey instrument which is $55.9 \%$ of total data collected. Age wise respondent's detail is presented in Fig. 1.

Experience: 92 respondents have experience of less than 3 years which makes $33 \%$ of the total respondents. 114 respondents belong to the experience slab of 3 to 5 years which is the $40.9 \%$ of the total respondents. 73 respondents have more than 5 years of experience which is $26.2 \%$ of the total respondents. Total $67 \%$ of our respondents have more than 3 years of experience which means that most of respondents have better knowledge about use of "Enterprise Resource Planning Systems".

Job Title: The category of the doctor includes respondents who are General Physicians, Hospitalist, Surgeons etc. similarly the medical staff includes persons performing medical related activities i.e. Lab technicians, nurses etc. The third category is of the respondents working in supportive departments i.e. administration department, information technology department, human resource etc. Fig. 2 shows Job title wise respondent's detail.

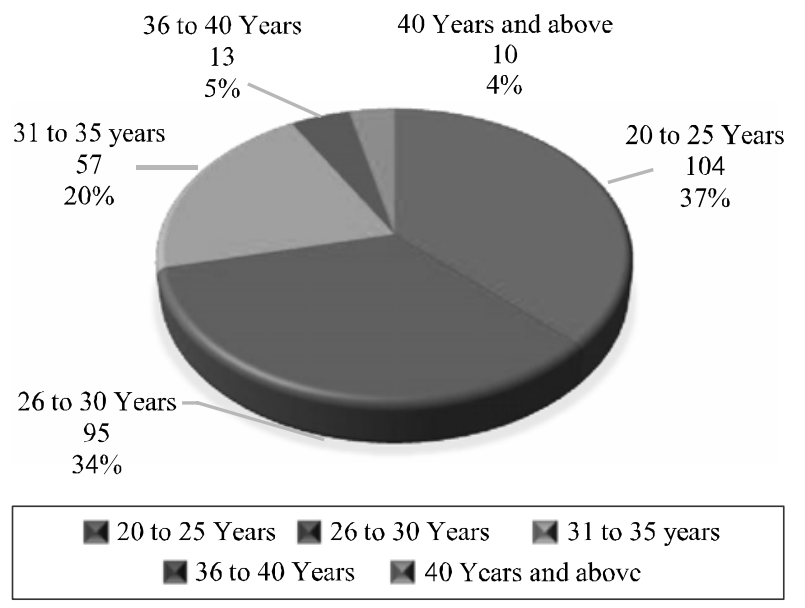

FIG. 1. AGE WISE RESPONDENT'S DETAIL

Mehran University Research Journal of Engineering \& Technology, Volume 35, No. 3, July, 2016 [p-ISSN: 0254-7821, e-ISSN: 2413-7219] 


\subsection{Individual Impact}

In order to study the individual impact of ERPS in healthcare services respondents were asked to answer the four questions on five point likert scale.

Learning through the Presence of ERPS: The first question in individual impact section was about the individual learning of the respondent while using ERPS. The question statement was "I have learnt much through the presence of ERPS". The question was asked on five point likert scale. 7 respondents which are $2.5 \%$ of the total data collected stated that they strongly disagree with the statement and similarly 10 respondents which are only $3.6 \%$ of total respondents also disagree with the statement. 38 respondents placed themselves as neutral which is $13.6 \%$ of the total respondents whereas 174 respondents which are $62.4 \%$ of total respondents agree with the statement and believe that use of ERPS results in individual learning. In the last 50 respondents which are $17.9 \%$ strongly agree with the statement.

Awareness About Job Related Information: In individual impact the second question is about the awareness and recall of job related information while using ERPS. The statement of the question was "ERPS enhances my

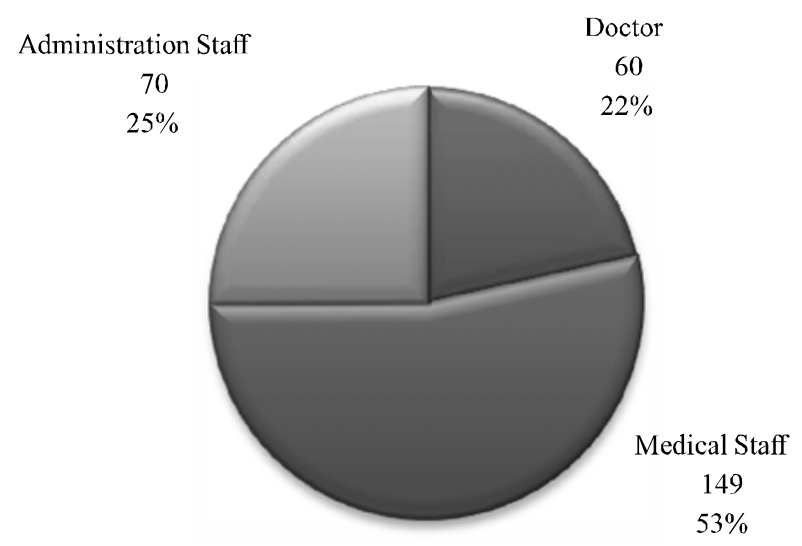

Doctor $\square$ Medical Staff $\square$ Administration Staff FIG. 2. JOB TITLE WISE RESPONDENT'S DETAIL awareness and recall of job related information" which is asked on five point likert scale. 7 respondents which is $2.5 \%$ of the total data collected stated that they strongly disagree with the statement and similarly 15 respondents which are only $5.4 \%$ of total respondents also disagree with the statement while 55 respondents placed themselves as neutral which is $19.7 \%$ of total respondents. There were 158 respondents on agree side which is 56.6 $\%$ on total respondents and similarly $15.8 \%$ of total respondents i.e. 44 respondents are of the view that they strongly agree with the statement. "Strongly agree" and "Agree" have more concentration as compared to other options i.e. $72.4 \%$ of the respondents are on this side. So we can conclude that use of ERPS enriches user's awareness of job related information.

Effectiveness in Job: In individual impact the third question was about the effectiveness in job while using ERPS. The statement of the question was "ERPS enhances my effectiveness in the job" which is asked on 5 point likert scale. 6 respondents which is $2.2 \%$ of the total respondents strongly believe that use of ERPS don't enhances user's job effectiveness similarly 33 respondents which is $11.8 \%$ of total respondents disagree with the statement. 38 respondents which are $13.6 \%$ of the total respondents answered their question with the option "Neither agree nor disagree". 159 respondents which are $57 \%$ of total respondents believe that the use of ERPS enhances the user's job effectiveness in the job. Last option of the question "strongly agree" received only 43 respondents which is $15.4 \%$ of the total respondents.

User's Productivity: Last question in individual impact was about productivity of individual user. The statement of the question was "ERPS increases my productivity" which is asked on five point likert scale. 6 respondents which are $2.2 \%$ of the total strongly disagree with the statement similarly only 22 respondents which are $7.9 \%$ 
of the total showed their disagreement with the statement. There are only 54 neutral respondents which are 19.4\% of the total. Most of the respondents are agree with the statement as 152 respondents which are $54.5 \%$ of the total are agreed with the statement. 45 respondents which are $16.1 \%$ of the total respondents selected the option "Strongly agree" for this question.

Overall Individual Impact: The overall individual impact of ERPS use was calculated by taking mean of all the responses. The mean for this dimension is 3.78 which shows respondents agreed that EPRs has a positive individual impact on users in healthcare services and hypothesis H1 is supported.

\subsection{Organizational Impact}

Cost Effectiveness: The first question in organizational impact was about the cost effectiveness of ERPS. The statement of the question was "ERPS is cost effective" which is asked on five point likert scale. 7 respondents which are $2.5 \%$ of the total respondents strongly believe that ERPS is not cost effective. Similarly only 15 respondents which are $5.4 \%$ of total respondents believe that ERPS is not cost effective. Considerable respondents i.e. 56 respondents which are $20.1 \%$ of the total respondents have placed themselves as neutral for this question. 59\% of the respondents are strongly agreed with the statement and believe that the use of ERPS is cost effective. 36 respondents which are $12.9 \%$ of total respondents strongly believe that ERPS is cost effective.

Reduced Staff Cost: The second question in organizational impact was about reduction in staff cost while using ERPS. The statement of the question was "ERPS has resulted in reduced staff costs" which is asked to be rated on five point likert scale. None of the respondents strongly disagree with the statement similarly 23 respondents which are $8.2 \%$ of total respondents disagree with the statement. Neutral respondents were 59 in numbers which are $21.1 \%$ of the total respondents. 132 respondents which are $47.3 \%$ of total respondents do agree with the statement while 65 respondents which are $23.3 \%$ of total respondents strongly agree with the statement. As option "Agree" has more concentration as compared to other options so we can conclude that a considerable reduction in staff cost is possible due to use of ERPS in healthcare services.

Reduction in Admin Cost: Third question in organizational impact was about the reduction in administration cost while using ERPS. The statement of the question was "ERPS has resulted in cost reductions (e.g. inventory holding costs, administration expenses, etc.)" which is asked to be rated on five point likert scale. 4 respondents out of 279 strongly disagree with the statement and $15.8 \%$ respondents believe that the use of ERPS cannot reduce administration cost in healthcare services. 67 respondents which are $24 \%$ of total respondents stated themselves as neutral for this statement. On the other side 124 respondents which are $44.4 \%$ of total respondents agree with the statement similarly 40 respondents which is $14.3 \%$ of total respondents do strongly agree with the statement.

Like previous questions, option "agree" and "strongly agree" have more concentration of respondents so we can conclude that the use of ERPS can reduce administration cost in healthcare services.

Improvement in Overall Productivity: The next question in organizational impact was about the improvement in overall productivity. The statement of the question was "ERPS has resulted in overall productivity improvement" which is asked to be answered on five point likert scale. 4 out of total 279 respondents strongly disagree with the statement while $7.5 \%$ of total respondents disagree with the statement. $28.7 \%$ of total respondents have neutral views about this question. On the agree side we have 152 respondent which are $54.5 \%$ of total respondents while 
22 respondents which are $7.9 \%$ of total respondents strongly disagree with this statement. Fig. 3 shows the graphical representation of this specific question. As most of the respondents' response concentration is on agree side so can easily conclude that overall productivity in healthcare services is increased while using ERPS.

Improvement in Output: Next question in organizational impact was about the improvement in overall outcomes while using ERPS. The statement of the question was "ERPS has resulted in improved outcomes or outputs" which is asked to be rated on five point likert scale. 7 respondents out of 279 strongly disagree with the statement and $8.2 \%$ respondents believe that the use of ERPS cannot increase outcome in healthcare services. 82 respondents which are $29.4 \%$ of total respondents stated themselves as neutral for this statement. There are 121 respondents on agree side which are $43.4 \%$ on total respondents and similarly $16.5 \%$ respondents i.e. 46 respondents are of the view that they strongly agree with the statement. It is clear in the graphic that option "Strongly Agree" and "Agree" have more concentration as compared to other options i.e. $59.9 \%$ of the respondents are on this side. So we can conclude that use of ERPS improves overall output in healthcare services.

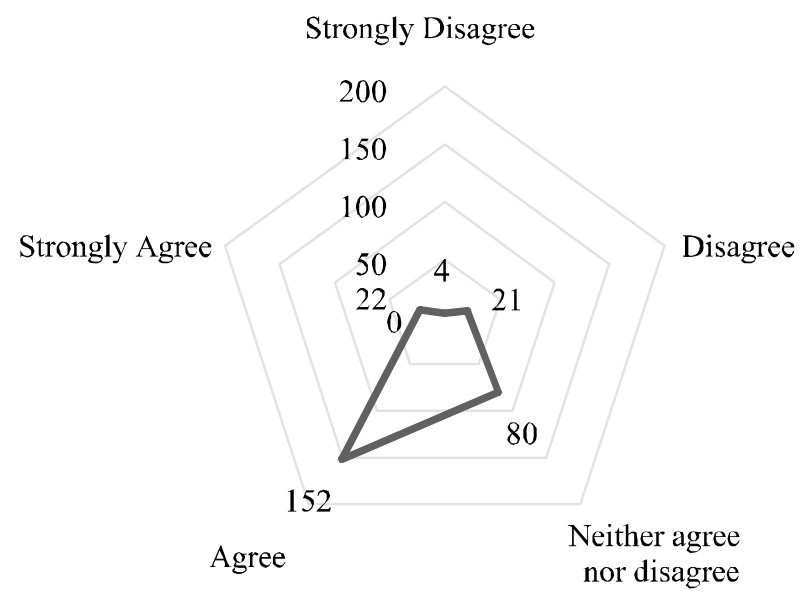

FIG. 3. IMPROVEMENT IN OVERALL PRODUCTIVITY
Increased Capacity: Next question in organizational impact is about the increased capacity of a healthcare organization while using ERPS. The statement of the question was "ERPS has resulted in an increased capacity to manage a growing volume of activity (e.g. transactions, population etc.)" which was asked to be rated on five point likert scale. 5 respondents out of 279 strongly disagree with the statement and 8.2\% respondents believe that the use of ERPS cannot increase capacity of healthcare organization. 63 respondents which are $22.6 \%$ of total respondents stated themselves neutral for this statement. There are 130 respondents on agree side which are $46.6 \%$ on total respondents and similarly $20.8 \%$ respondents i.e. 58 respondents are of the view that they strongly agree with the statement. Option "Strongly Agree" and "Agree" have more concentration as compared to other options i.e. $67.4 \%$ of the respondents are on this side. So we can conclude that use of ERPS enhance the capacity of a healthcare organization to deal with larger volume of transactions.

Better E-Governance: Next question in organizational impact was about the better positioning for e-governance of a healthcare organization while using ERPS. The statement of the question was "ERPS has resulted in better positioning for e-Government." which is asked to be rated on five point likert scale. 3 respondents out of 279 strongly disagree with the statement and 39.8\% respondents believe that the use of ERPS cannot increase the positioning for e-governance of a healthcare organization. 113 respondents which are $40.5 \%$ of total respondents stated themselves as neutral for this statement.

There are 47 respondents on agree side which are $16.8 \%$ on total respondents and similarly $1.8 \%$ respondents i.e. 5 respondents are of the view that they strongly agree with the statement. $40.9 \%$ respondents either disagree or strongly disagree with this statement which is higher than other options so we can conclude that the use of ERPS do not results in better e-governance. 
Improved Business Process: Last question in organizational impact was about the improvement of business processes while using ERPS. The statement of the question is "ERPS has resulted in improved business processes." which is asked to be rated on five point likert scale. 6 respondents out of 279 strongly disagree with the statement and $3.9 \%$ respondents believe that the use of ERPS cannot improve the business processes in healthcare service organization.

63 respondents which are $22.6 \%$ of total respondents stated themselves as neutral for this statement. There are 137 respondents on agree side which is $49.1 \%$ of total respondents and similarly $22.2 \%$ respondents i.e. 62 respondents are of the view that they strongly agree with the statement. "Strongly agree" and "Agree" have more concentration as compared to other options i.e. $71.3 \%$ of the respondents are on this side. So we can conclude that use of ERPS improves overall business processes in healthcare services.

Overall Organizational Impact: The overall organizational impact of ERPS use was calculated by the taking mean of all the responses for all questions in organizational impact dimension. The mean for this dimension is 3.59 which shows respondents agreed that EPRs has a positive organizational impact in healthcare services and hypothesis $\mathrm{H} 2$ is also supported.

\section{CONCLUSION}

The use of ERPS in healthcare services had both positive individual and organizational impact. In individual impact there was learning through the presence of ERPS, increased awareness about job related information, effectiveness in job and user's productivity. In organizational impact the use of ERP was cost effective and it resulted in reduced staff and administration cost. Overall productivity in healthcare services increased while using ERPS. ERP improves overall output in healthcare services. Use of ERPS enhances the capacity of a healthcare organization to deal with larger volume of transactions. Use of ERPS did not resulted in better egovernance. The use of ERPS improves overall business processes in healthcare services. This study will help healthcare organizations to better find individual and organizational impacts.

\section{ACKNOWLEDGEMENT}

Authors wish to express their sincere thanks to Dr. Muhammad Shoaib, Director, Institute of Business \& Management, University of Engineering \& Technology, Lahore, Pakistan, for providing us with all the necessary facilities for the research and for the continuous encouragement.

\section{REFERENCES}

[1] Al-Mashari, M., Al-Mudimigh, A., and Zairi, M., "Enterprise Resource Planning: A Taxonomy of Critical Factors", European Journal of Operational Research, Volume 146, pp. 352-364. 2003.

[2] Kumar, K., and Hillegersberg, J.V., "ERP Experiences and Evolution", Communications of the ACM, Volume 43, pp. 23-26, 2000.

[3] Soh, C., Kien, S., and Tay-Yap, J., "Cultural Fits and Misfits: Is ERP a Universal Solution?", Communication of the ACM, Volume 43, pp. 47-51, 2000.

[4] Somers, T.M., and Nelson K.G., "The Impact of Critical Success Factors across the Stages of Enterprise Resource Planning Implementations", Proceedings of $34^{\text {th }}$ Hawaii International Conference on System Sciences, 2001.

[5] Markus, M.L. "Technochange Management: Using it to Drive Organizational Change", Journal of Information Technology, Volume 19, pp. 4-20, 2004.

[6] Thatcher, M.E., and Oliver, J.R., "The Impact of Technology Investments on a Firm's Production Efficiency, Product Quality, and Productivity”, Journal of Management Information System, Volume 18, pp. 17-45, 2001. 
[7] Singla, A.R., "Impact of ERP Systems on Small and Mid-Sized Public Sector Enterprises", Journal of Theoretical and Applied Information Technology, pp. 119-131, 2005.

[8] Sally, W., and Wright, A.M., "Information System Assurance for Enterprise Resource Planning Systems: Unique Risk Considerations", Journal of Information Science, Volume 16, pp. 99-113, 2002.

[9] Daniel, E., and O'Leary, "Information System Assurance for ERP Systems: Unique Risk Consideration”, Journal of Information System, Volume 16, pp. 115-126, 2002.

[10] Umble, E.J., and Umble, M.M., "Avoiding ERP Implementation Failure", Industrial Management, pp. 26-33, 2003.

[11] David, K. Thomas, K., and Havenhand, M., "ERP Critical Success Factors: An Exploration of the Contextual Factors in Public Sector Institutions", Proceedings of $35^{\text {th }}$ Annual Hawaii International Conference on System Sciences, 2002.

[12] Yusof, M. M., Papazafeiropoulou, A., Paul, R.J., and Stergioulas, L.K., "Investigating Evaluation Frameworks for Health Information Systems", International Journal of Medical Information, Volume 77, pp. 377-85, 2008,

[13] Adler-Milstein, J., and Bates, D.W., "Paperless Health Care: Progress and Challenges of an IT-Enabled Health Care system", Business Horizons, Volume 53, pp. 119-130, 2010.

[14] Acharyulu, G.V.R.K., “Assessment of Hospital Information System Quality in Multi Specialty Hospitals", International Journal of Industrial Management Technology, Volume 3, pp. 349-352, 2012.

[15] Hsu, L.L., and Chen, M., "Impacts of ERP Systems on the Integrated-Interaction Performance of Manufacturing and Marketing", Industrial Management Data System, Volume 104, pp. 42-55, 2004.

[16] Merodea, G., Groothuisb, S., and Hasmanb, A., "Enterprise Resource Planning for Hospitals", International Journal Medical Information, Volume 73, pp. 493-501, 2004.
[17] McGinnis, S.K., Pumphrey, L., Trimmer, K., and Wiggins, C.A., "Case Study in IT Innovation in a Small, Rural Community Hospital", Research Healthcare Finance Management, Volume 9, pp. 9-19, 2004.

[18] Trimmer, K.J., Pumphrey, L.D., and Wiggins, C., "ERP Implementation in Rural Health Accountant and Researching His Reality", Accounts Organization Society, Volume 8, pp. 361-374, 2002.

[19] Escobar-Pérez, B., and Escobar-Rodríguez, T., "ERP Systems in Hospitals: A Case Study", Journal of Information Technology Research, Volume 10, pp. 104-112, 2010.

[20] Gable, G.G., Sedera, D., and Chan, T., "Re-Conceptualizing Information System Success: The IS-Impact Measurement Model", Journal of Association Information System, Volume 9, pp. 377-408, 2008.

[21] Rai, A., Patnayakuni, R., and Seth, N., "Firm Performance Impacts of Digitally Enabled Supply Chain Integration Capabilities", MIS Quarterly, Volume 30, pp. 225-246, 2006.

[22] Kearns, G.S., and Lederer, A.L., "The Impact of Industry Contextual Factors on IT Focus and the Use of IT for Competitive Advantage", Information Management, Volume 41, pp. 899-919, 2004.

[23] Melville, N., Kraemer, K., and Gurbaxani, V., "Review: Information Technology and Organizational Performance: An Integrated Model of Business Value", MIS Quarterly, pp. 283-322, 2004.

[24] Sethi, V., and King, W.R., "Development of Measures to Assess the Extent to which an Information Technology Application Provides Competitive Advantage", Management Science, Volume 40, pp. 1601-1627, 1994.

[25] Barua, A., Kriebel, C.H., and Mukhopadhyay, T., "Information Technologies and Business Value: An Analytic and Empirical Investigation”, Information System Research, Volume 6, pp. 3-23, 1995. 